\title{
Complications of blunt versus sharp expansion of the uterine incision in lower segment caesarean section. A randomized controlled trial
}

\author{
D.M.C.S. Jayasundara MBBS, MD, MRCOG $^{1}$, R.N.G. Rajapakse MBBS, MS. ${ }^{2}$
}

\begin{abstract}
Introduction: Caesarean section has now become the most frequently performed major surgical procedure in women in the field of Obstetrics and Gynaecology. There is however a wide variation in the surgical technique of caesarean section. Our objective was to compare incidence of complications associated with blunt versus sharp expansion of the uterine incision at the time of caesarean section.
\end{abstract}

Methods: 274 women who underwent a lower segment caesarean section at North Colombo Teaching Hospital, Ragama was assigned randomly to have the expansion of the primary uterine incision either bluntly using the index fingers of both hands of the surgeon or sharply using a curved scissors. Rest of the surgery was performed alike in all participants.

Results: The blunt expansion group ( $n=141)$ and the sharp expansion group $(n=133)$ were similar with regard to age distribution, BMI, parity, history of previous LSCS and proportion of elective or emergency procedures and the cervical dilatation at the time of LSCS. The incidence of inadvertent extensions ( $42.1 \%$ vs $28.4 \%$; $p=0.02$ ) and the mean time taken to repair the uterine incision (14.9min vs $13.7 \mathrm{~min} ; \mathrm{p}=0.03$ ) was significantly higher in the blunt expansion group compared to the sharp expansion group. The percentage drop in haematocrit more than $10 \%$ ( $30.8 \%$ vs $28.4 \% ; p=0.48)$ and the drop in haemoglobin more than $2 \mathrm{~g} / \mathrm{dl}(22.6 \%$ vs $20.6 \% ; \mathrm{p}=0.47)$ was not significantly different in the blunt expansion group compared to the sharp expansion group. Incidence of inadvertent extensions was significantly different ( 38.5 vs $24.1 ; p=0.03$ ) during elective LSCS but not during emergency LSCS ( $50 \%$ vs $44.8 \% ; p=0.67$ ) between the blunt expansion group and sharp expansion group. The incidence of inadvertent extensions was significantly higher (36.5\% vs $24 \%$; $p=0.03$ ) when the cervical dilatation was less than $4 \mathrm{~cm}$ at the time of LSCS in the blunt expansion group compared to the sharp expansion group. Blunt expansion group required more blood pint transfusions when compared to the sharp expansion group (6 vs 2).

Conclusion: The sharp expansion of the uterine incision at the time LSCS is associated with a lower risk of inadvertent extensions as well as extensions into broad ligament and uterine vessels compared to the blunt expansion method.

The sharp expansion of the uterine incision is preferable to blunt expansion during LSCS and its advantage is more evident during elective LSCS than during emergency LSCS and when the cervical dilatation was less than $4 \mathrm{~cm}$ at the time of LSCS.

\section{INTRODUCTION}

Caesarean section can be defined as delivery of the fetus throughanincision in the abdominal wall (laparotomy) and the uterine wall (hysterotomy) [1] Caesarean section has evolved during the $20^{\text {th }}$ century to become a relatively

\footnotetext{
${ }^{1}$ University of Peradeniya and Teaching Hospital Peradeniya

${ }^{2}$ Colombo Teaching Hospital, Ragama.
}

Correspondence: Dr Chandana Jayasundara

E-mail: chandanasj@yahoo.com

Competing interests: None safe procedure largely because of improved anaesthetic techniques, antiseptic procedures and surgical technique of lower segment caesarean section [2]. The rate of delivery by caesarean section has increased at an accelerated pace during the last 2-3 decades in the developed as well as in the developing countries [1, 3, 4]. From 1990 onwards, most countries observed a progressive increase in caesarean births and women are now four times more likely to have a caesarean birth than 30 years ago [5]. Though the caesarean section has now become the most frequently performed major surgical procedure in women in the field of obstetrics and gynaecology [6], there is however a wide variation in the surgical technique used as well as the quality of evidence to support these techniques [6]. Of the methods used for uterine incision to deliver the baby, the commonest incision now used in modern obstetrics is the lower transverse uterine incision, which accounts for about $98 \%$ of all uterine incisions [7]. The first recorded lower segment transverse uterine incision is credited to Frank in 1906 [2]. But it was popularized by Munro-kerr in 1926 [4].

This is done by placing an initial incision by an scalpel using a gentle featherweight stroke and then expanding this incision laterally either bluntly using the two index fingers or sharply using the scissors [2].

There is an ongoing debate about which of these forms of uterine entry, i.e., sharp or blunt, results in better maternal and fetal outcome. Theoretical benefits of sharp uterine incision include rapid delivery of the baby, more controlled entry, less likelihood of incision entering the broad segment or uterine vessels and easier repair. Benefits of blunt uterine entry are that the incision follows the tissue planes thus reducing blood loss, improves healing and less infant lacerations [8].

The comparison of blunt and sharp extension of the uterine incision has been compared in a randomized trial involving 286 women. Here there was no significant difference in the incidence of unintended uterine incisions, intra operative duration or estimated blood loss [9]. In another study, which included 945 women, it was reported that sharp extension is associated with greater estimated blood loss and a greater incidence of post-partum haemorrhage and need for transfusion [10]. On the other hand a non-randomized clinical trial 
in Pakistan on comparison of blunt vs. sharp expansion of the uterine incision reported a significant increase in blood loss, need for transfusion and inadvertent extension of incision in the blunt group compared to sharp group [11]. From this description it is evident that conclusive data are lacking from large randomized control trials comparing the surgical technique for uterine incision in caesarean section and though caesarean section is a common surgical procedure performed in women there is little information available to decide on the most appropriate technique for uterine incision that is easy to perform and associated with least complications and easy to repair. In addition there is lack of evidence comparing complications of either technique of uterine incision with dilatation of cervix and urgency of the procedure.

So the purpose of our study to compare incidence of complications associated with blunt versus sharp expansion of the uterine incision at the time of caesarean section. Of the complications we looked into unintended extensions of primary incision laterally or inferiorly between the two methods, percentage drop in HCT between these methods, and the mean time taken in either method from start of uterine incision to closure of uterine incision. We also analyzed the incidence of unintended extensions of the incision to the broad ligament, uterine vessels and cervix, the complications occurring when the dilatation of the cervix is less than $4 \mathrm{~cm}$, $4 \mathrm{~cm}$ to $9 \mathrm{~cm}$ or $10 \mathrm{~cm}$, The occurrence of post-partum haemorrhage, which is determined by reduction in haematocrit by more than $10 \%$, complications with either technique during elective and emergency LSCS, need for blood transfusion and Any fetal injuries acquired during the procedure in either technique.

\section{METHODS}

This was a randomized control trial without blinding conducted in North Colombo Teaching Hospital (NCTH) Ragama Sri Lanka. The study was conducted from December 2008 to April 2009.
Sample size \& power calculation was done. It was determined that 250 women in each group was sufficient power (power of 0.80, a error of $0.05 \& \beta$ error $=0.20$ ) to demonstrate a difference of $10 \%$ (25\%vs $15 \%)$ of unintended tears between groups [12]. These calculations were based on a previous study in which the unintended extensions between the two methods were approximately $25 \%$ versus $15 \%$ [10] but an interim analysis was done halfway through the study after recruiting 274 participants which included 133 in the sharp expansion group and 141 in blunt expansion group who underwent through the complete trial. Here we found that the percentage of unintended extensions, which was our primary outcome measure, was significantly higher in the blunt expansion group compared to the sharp expansion group. Thus trial was terminated half way through as it was unethical to continue the trial once we have seen a significant benefit in sharp expansion group compared to the blunt expansion group

All consecutive women admitted to the antenatal ward for delivery was informed about the study, consent obtained and included in the study.

This included all mothers who underwent LSCS from the antenatal ward and labour room either as an emergency or an elective procedure.

We excluded all women who refuse randomization as they prefer either technique or for any other reason, Women who had an increased risk of bleeding like Placental abruption / placenta previa, Uterine fibroid at lower segment, Fever with suspected chorioamnionitis, Inherited/ acquired bleeding disorders, Severe PIH on $\mathrm{MgSO}_{4}$ Extreme premature cases where lower segment has not formed was excluded from the study (less than 30 weeks), And all women who underwent general anaesthesia were excluded as this is associated with increased bleeding [13].

After completion of informed consent the women were randomized to group A (sharp) or group B (blunt) using block randomized computer generated list. All operative procedures done before the uterine incision was performed similarly in all the mothers [2]. The assigned treatment is written in a card and sealed in secure opaque envelopes.

In the sharp expansion method a transverse uterine incision in the lower uterine segment of approximately $2 \mathrm{~cm}$ in length was made with the scalpel. The uterine incision was expanded by cutting laterally and cephalad using curved scissors. And in the blunt expansion method, after placing the $2 \mathrm{~cm}$ transverse incision by scalpel in the lower uterine segment, this was expanded using the index fingers of both hands placed into the incision and pulling the fingers laterally and cephalad. The placenta was delivered using controlled cord traction unless it is morbidly adhered and if so was documented. After the delivery of the baby $5 u$ of oxytocin was given by slow IV to every woman. Additional oxytocin infusion (20u in 500cc Normal Saline) was given only if bleeding is more and was documented. The use of additional uterotonics (ergometrine, misoprostol) was recorded. The closure of the uterus was with 1 or 2 vicryl in double layers. The time for starting the uterine incision to completion of uterine repair was recorded with a stop watch and any part of the minute was taken as the next full minute. The remainder of the operation was performed alike in all patients [2].

An extension of the primary incision was defined as any defect which is observed outside the limits of the original incision in uterine tissue. This was decided by surgeon and the assisting house officer at the time of surgery, in any disagreement the opinion of a third team member was sought to come to an agreement. The extension into broad ligament, uterine vessels and/or cervix was recorded separately.

All caesarean sections were performed by the obstetrician, registrar and two other experienced senior house officers (SHOs) in the unit. All of the surgeon had performed more than 1000 lower segment caesarean sections individually and were well experienced in both techniques of uterine expansion. 
The blood loss was assessed by comparing theimmediatepreoperative haematocrit which is drawn in the ward prior to sending the patient to the theatre, with a $2^{\text {nd }}$ haematocrit 48hours after the surgical procedure and the percentage reduction in haematocrit was calculated. The need for blood transfusion was recorded.

Data was collected in a data collection sheet and entered into a computer database on a daily basis. The data sheet was filled by the surgeon and the house officer $(\mathrm{HO})$. The data sheet was attached to the BHT of every mother taken to theatre for LSCS. Data

Figure 1 Flow of participants through each stage of the randomization clinical trial

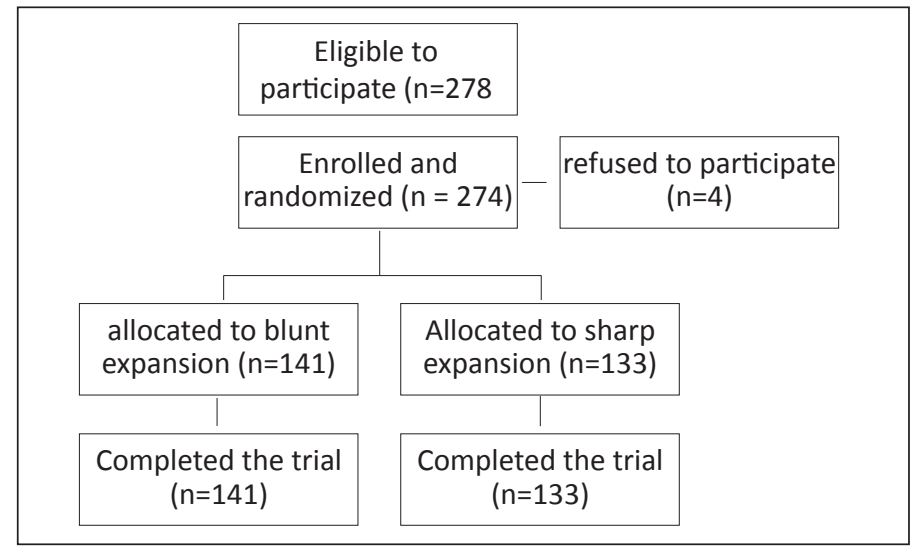

Table 1:- Clinical characteristics of the study groups

\begin{tabular}{|c|c|c|c|}
\hline Characteristics & $\begin{array}{l}\text { BLUNT EXPAN- } \\
\text { SION }\end{array}$ & $\begin{array}{l}\text { SHARP EX- } \\
\text { PANSION }\end{array}$ & P VALUE \\
\hline Maternal age & $29.8 \pm 4.8$ & $30.0 \pm 5.0$ & 0.79 \\
\hline Nulliparous & $60(42.1 \%)$ & $60(42.6 \%)$ & 0.67 \\
\hline Multiparous & 73 (54.9\%) & $81(57.4)$ & 0.67 \\
\hline BMI & & & 0.12 \\
\hline underweight & $1(0.8 \%)$ & $1(0.9 \%)$ & \\
\hline normal & $50(37.6 \%)$ & $42(29.8 \%)$ & \\
\hline overweight & $46(34.6 \%)$ & $66(46.8 \%)$ & \\
\hline obese & $37(27.1 \%)$ & $32(22.7 \%)$ & \\
\hline past caesarean section & $51(38.3 \%)$ & $58(41.1 \%)$ & 0.64 \\
\hline urgency & & & 0.05 \\
\hline elective LSCS & $91(68.4 \%)$ & $112(79.4 \%)$ & \\
\hline emergency LSCS & $42(31.6 \%)$ & $29(20.6 \%)$ & \\
\hline \multicolumn{4}{|l|}{ cervical dilatation } \\
\hline$<4 \mathrm{~cm}$ & $115(86.5 \%)$ & $125(88.7 \%)$ & 0.34 \\
\hline $4 \mathrm{~cm}-9 \mathrm{~cm}$ & $14(10.5 \%)$ & $12(8.5)$ & 0.34 \\
\hline fully dilated & $4(3 \%)$ & $4(2.8 \%)$ & \\
\hline operating time & $14.9+-4.7$ & $13.7+-4.4$ & $0.03(\mathrm{~S})$ \\
\hline
\end{tabular}

This project proposal was submitted to the ethics committee of the clinical trials unit of Faculty of Medicine, University of Kelaniya and approval obtained. This trial was registered in the "Sri Lanka Medical Association clinical trial registry" as randomized controlled clinical trial.

\section{RESULTS}

After considering the inclusion criteria and exclusion criteria 278 women were eligible for the trial up to interim analysis and all were invited to participate. Of this 278 women 4 women declined to participate which left a total of 274 women who voluntarily consented and participated in the prospective randomized trial.

Of the 274 participants 133 were enrolled to the sharp expansion of the uterine incision group and 141 were enrolled to the blunt expansion of the uterine incision group and under went through the complete trial. (Figure1). Women who participated in trial had similar base line obstetric and demographic characteristic in term of maternal age, parity and body mass index (Table 1), the age of blunt expansion group ranged from 21-40 years with a mean of 29.8 yrs +/- 4.8 yrs. While the age of sharp expansion group ranged from 18-44 years with a mean of 30 years $+/-5$ years. The body mass index was calculated.

All the women underwent the assigned method of expansion (blunt or Sharp) and neither group required either $\mathrm{J}$ or $\mathrm{T}$ incision to deliver the baby. And none of the selected women needed caesarean hysterectomy as a lifesaving surgery. Table 2 displays the complications associated with blunt and sharp technique. There were 56 tears out of 133 women $(42.1 \%)$ in the blunt uterine expansion group compared to 40 tears out of 141 women in the sharp uterine expansion group $(28.4 \%)$. This difference was statistically significant. $(p=0.02)$ the majority of these tears were less than $2 \mathrm{~cm}(67.9 \%$ in blunt expansion and $60.0 \%$ in sharp expansion method). Extension in to broad ligament occurred in $9(6.8 \%)$ in blunt and 7 $(5.0 \%)$ in sharp group and extension 
Table 2:- Comparison of complications associated with blunt and sharp expansion method

\begin{tabular}{|l|l|l|l|}
\hline complication & $\begin{array}{l}\text { blunt } \\
\text { expansion }\end{array}$ & $\begin{array}{l}\text { sharp } \\
\text { expansion }\end{array}$ & P value \\
\hline inadvertent extensions & $56(41.2 \%)$ & $40(28.4 \%)$ & 0.02 \\
\hline inadvertent extension $>2 \mathrm{~cm}$ & $18(32.1 \%)$ & $16(40.0 \%)$ & 0.43 \\
\hline extension to broad ligament & $9(6.8 \%)$ & $7(5.0 \%)$ & 0.33 \\
\hline extension to uterine vessels & $6(4.5 \%)$ & $2(1.4 \%)$ & 0.13 \\
\hline extension to cervix & $1(0.8 \%)$ & $1(0.7 \%)$ & $* *$ \\
\hline tears during emergency LSCS & $35(38.5 \%)$ & $27(27.1 \%)$ & 0.03 \\
\hline tears during elective Iscs & $21(50 \%)$ & $13(44.8 \%)$ & 0.67 \\
\hline tears when cervix $<4 \mathrm{~cm}$ & $42(36.5 \%)$ & $30(24.0)$ & 0.03 \\
\hline tears when cervix 4-9cm & $10(71.4 \%)$ & $6(50.0 \%)$ & 0.47 \\
\hline tears when fully dilated & $4(100 \%)$ & $4(100 \%)$ & $* *$ \\
\hline percentage drop in Haematocrit $>10 \%$ & $41(30.8 \%)$ & $40(28.4 \%)$ & 0.48 \\
\hline $\begin{array}{l}\text { drop of Haemoglobin pre op and post op } \\
48 \text { hours >2 G/dl }\end{array}$ & $30(22.6 \%)$ & $29(20.6 \%)$ & 0.47 \\
\hline
\end{tabular}

into uterine vessels occurred in 6 $(4.5 \%)$ in blunt and $2(1.4 \%)$ in sharp group, tears extending into cervix occurred 1 each in either method $(0.8 \%$ Vs $0.7 \%)$. In subgroup analysis we found that during elective Lower segment caesarean section (LSCS) $35(38.5 \%)$ tears occurred with blunt technique while 27 (24.1\%) occurred with sharp technique this finding was statistically significant $(p=0.03)$. There were 21 tears $(50 \%)$ in blunt group compared to $13(44.8 \%)$ tears in the sharp group during emergency LSCS. This difference was not statistically significant

$(p=0.67)$. when considering the cervical dilatation when the LSCS was performed There were $42(36.5 \%)$ tears in the blunt group when compared to $30(24 \%)$ tears in the sharp group when the LSCS was performed at cervical dilatation less than $4 \mathrm{~cm}$. this difference was statistically significant $(p=0.03)$. Inadvertent extensions in either group was not statistically significant in either method when LSCS was performed between $4 \mathrm{~cm}$ $9 \mathrm{~cm}$ and when performed when fully dilated (table 2). The percentage drop in haematocrit $>10 \%$ and drop in haemoglobin $>2 \mathrm{~g} / \mathrm{dl}$ from preoperative value to 48 hours postoperative value was not significant in either method of expansion ( table 2 ).

The need for blood transfusions was more in blunt expansion group (5) when compared to the sharp expansion group (2). The mean time taken to repair the uterine incision in blunt expansion group was $14.9 \mathrm{~min}$ compared to 13.7 in sharp expansion group this difference was statistically significant $(\mathrm{p}=0.03)$.

\section{DISCUSSION}

The main objective of our trial was to determine whether a specific technique of uterine incision during lower segment caesarian section, blunt versus sharp expansion of the uterine incision was associated with increased risk of unintended extensions into the uterine tissue.

The result we obtained indicated that sharp expansion technique of the uterine incision is associated with a lower risk of unintended extensions significantly compared to the blunt expansion technique.

The reported advantage of the sharp expansion of the uterine incision over the blunt expansion of the uterine incision is that it can be done precisely and therefore avoid unintended injury to uterine vessels and parametrial tissue ${ }^{22}$. But this technique needs more experience and training to perform than the blunt expansion technique, which can be done with relatively higher speed and ease and also requires less experience. We acknowledge the potential difficulty in determination of presence or absence of inadvertent extensions of the uterine incision due to the subjective nature of its assessment. But it should be commented that this potential bias will affect both groups of the study and thus should not alter the final outcome. Another disadvantage which has to be mentioned in blunt uterine expansion technique is the higher incidence of unintended extensions of the uterine incision into the uterine vessels or inferiorly to broad ligament, if the fingers of the surgeon are swept too far laterally [14]. And it has been stated that, in fact the maximum traction force is exerted at the lateral most edge of the uterine incision in the blunt expansion technique [14]. In our study we also found that the number of unintended extensions to broad ligament and uterine vessels was lower in the sharp expansion group when compared to the blunt expansion group, but this value was not statistically significant. This disadvantage of the blunt expansion technique had been mentioned in previous studies as well [15].

An interesting finding in our study was that the number of unintended extensions during uterine incision expansion was significantly less with sharp expansion technique compared to the blunt expansion technique during elective lower segment caesarian section. But this was not the case in emergency lower segment caesarian section where the number of unintended extensions was not significantly different between the two techniques. This might be due to the fact that in elective lower segment caesarian section the sharp expansion of the uterine incision can be performed more precisely and in a controlled manner than the blunt uterine expansion technique. 
This observation gained more credence when we also observed that the number of unintended extensions was significantly lower in the sharp uterine expansion group compared to the blunt uterine expansion group when the cervical dilatation was less than $4 \mathrm{~cm}$ at the time of LSCS. But the number of unintended extensions was not significantly different between the two techniques when the LSCS was done when the cervical dilatation was $4 \mathrm{~cm}-9 \mathrm{~cm}$ or when the cervix was fully dilated.

Above findings suggest that sharp expansion of uterine incision is the more safer and superior technique when performed during elective lower segment caesarian section or when the woman was not in active labour or in early labour with the fetal head not well descended into the maternal pelvis and that the blunt expansion technique may be the more suited technique in acute situations such as emergency lower segment caesarian section or when lower segment caesarian section was performed beyond a cervical dilatation of more than $4 \mathrm{~cm}$ due to the fact that sharp uterine expansion technique carries a theoretical risk of foetal damage from the scissors[8] if the surgeon performs this technique in a hurry without trying to visualize the surgical field adequately

The other important outcome that has to be considered when comparing the blunt expansion and sharp expansion of the uterine incision is the estimated blood loss in either technique. It has been argued that sharp expansion method is associated with higher blood loss due to bleeding from incision itself by muscle ooze or traumatized vasculature [10]. In our study we did not find a significant difference of the percentage blood loss between sharp uterine expansion group and the blunt uterine expansion group. More women in the blunt group received blood transfusion when compared to the sharp group in our study.

The time taken to repair the uterine incision was calculated by measuring the time taken from the start of uterine incision to complete repair of the uterine incision and to achieve haemostasis, this was done using a stopwatch. In our study we found that the mean time taken to complete the repair of the uterine incision was significantly lower in sharp expansion group compared to blunt expansion group. The presence of clean edges in sharp uterine expansion method probably helps in quick repair of incision. The time difference was not analyzed in previous studies and though statistically significant, in practical and clinical consideration, this difference probably has little importance as the mean difference is just more than $1 \mathrm{~min}$ between the two methods.

\section{CONCLUSION}

The sharp expansion of the uterine incision at the time LSCS is associated with a lower risk of inadvertent extensions as well as extensions into broad ligament and uterine vessels compared to the blunt expansion method.

The sharp expansion of the uterine incision is preferable to blunt expansion during LSCS and its advantage is more evident during elective LSCS than during emergency LSCS and when the cervical dilatation was less than $4 \mathrm{~cm}$ at the time of LSCS.

The results of our study also suggested that there was no difference in the risk of intra operative or postpartum haemorrhage between the sharp uterine expansion and the blunt uterine expansion techniques during the lower segment caesarean section.

Sharp uterine expansion method can be repaired faster than the blunt uterine expansion method and the need for blood transfusion is less with sharp uterine expansion method.

口

\section{REFERENCES}

[1] Caesarean section \& caesarean hysterectomy. In : Cunnigham FG, Macdonald PC, Leveno KG, Gant NF, Gilstrap III LC. Editors. Williams Obstetrics : $19^{\text {th }}$ edition. New York : Appleton \& Lange 1993: 591-613

[2] Chamberlain G, Caesarean section. In:Chamberlain G, Steer $P$, editors.
Turnbulls Obstetrics(3 $3^{\text {rd }} \quad$ ed).New York:Churchill Livingstone,2001:601-617

[3] Leone T, Padmadas SS, Mathews Z. Community factors affecting rising caesarean section rates in developing coutries: an analysis of six countries.Soc Sci Med 2008;67(8):1236-1246.

[4] Berghella V, Baxter JK, Chauhan SP. Evidence based surgery for caesarean delivery. Am J Obstet Gynecol 2005; 193: 1607-1617.

[5] Ushakiran TS, Jayawickrama NS. Who is responsible for the rise in LSCS rate. J Obstet gynaecol 2002; 22:363-365

[6] Tully L, Gates S, Brockelhurst P. Surgical techniques used during caesarean section operations, results of a national survey of practice in the UK. Eur J Obstet Gynaecol Reprod Biol 2002;102:120-125

[7] Patterson LS, O'Connell CM, Baskett TF. Maternal and Perinatal Morbidity Associated with Classic and Inverted T Caesarean Sections. Obstet Gynaecol 2002; 100:633-637.

[8] Dodd JM, Anderson LB, Gates S. Surgical technique involving the uterine incision at the time of caesarean section (protocol) 2007; the cochrane collaboration: issue1

[9] Rodriguez JN, Porter KB, OBrien WF. Blunt versus sharp expansion of the uterine incision in low segment transverse caesarean section. Am J Obstet Gynecol 1994;171:1022-1025

[10] Magann EF, Chauhan SP, Bufkin L, Field K, Roberts WE, Martin Jr JN. Intra operative haemorrhage by blunt versus sharp expansion of the uterine incision at caesarean delivery a randomized clinical trial. Br J Obstet Gynaecol 2002;109:448452.

[11] Hameed N, Muhammed AA, Maternal blood loss by uterine incision at caesarean section, A comparison between sharp \& blunt techniques. J Ayub Med Coll Abbottabad 2004; 16(3)47-50.

[12] Lwanga SK, Lemeshnow S. editors. Sample size calculation in health studies : a practical manual. Table 5

[13] Combs CA, Murphy EL,Laros RK. Factors associated with haemorrhage in caesarean deliveries. Obstet gynecol1991;77:77-82.

[14] Cromi A, Ghellzi F, Di Naro E, Siesto G, Loverro G, Bolis P. Blunt expansion of the lower transverse uterine incision at caesarean delivery. Am J Obstet Gynecol 2008; 199: 292e1-e6.

[15] Jananoul R. Incision of the pregnant uterus and delivery of low birth weight infants. Am J Obstet Gynecol 1985;152:971-974 